\title{
Miscellany
}

Fans-Jörg Weitbrecht Scientific Award This prize for exceptional scientific achievements, sponsored by Bayar Vital, Business Group Pharma, Leverkusen, and endowed with 10.000-DM will be awarded for the sixth time in 1998. All papers should reach the board of trustees no later than 30 November. Further information: Professor Dr med. Dr h.c. Gerd Huber, Universitäts-Nervenklinik, D-53105 Bonn (Venusberg), Germany. (Fax: +49 228/32 28 83).

\section{Job opportunities for people with mental health problems}

For the first time, people with mental health problems are to be encouraged to apply for any post (qualified or non-qualified) which falls vacant at Springfield University Hospital in Wandsworth. The new initiative is the result of the hugely successful User Employment Project set up by Pathfinder Mental Health Services NHS Trust two years ago. Further information: $\mathrm{Mr}$ Duncan Selbie on 01816826385.

\section{Neglected health needs of people with dementia in care homes}

The recently published findings of an Alzheimer's Disease Society survey of 1500 carers, suggests that the health needs of many people with dementia are being neglected while cared for in a residential or nursing home. In the survey $49 \%$ of carers said they felt that the support received from the GP in the home was poor or no better than average. Only $23 \%$ said the support was excellent. The society's report concludes that carers' experiences are a strong indicator that many drugs are being inappropriately used, probably for the benefit of care home staff rather then the person with dementia. This reinforces recent recommendations from the Royal College of Physicians about the overuse of sedative drugs on older people. The report calls for new Department of Health Guidance on the prescribing of such drugs. Further information: Press Office on 01713060813 .

\section{Cherie Booth launches CarersLine}

A new telephone information service for carers has been launched by Cherle Booth $\mathrm{QC}$, for Carers National Association (CNA). The CarersLine, made possible by the National Lottery Charities Board, will provide carers with expert advice on all aspects of caring, at the cost of a local phone call. In addition, the CNA has published a series of 14 information booklets, which are available free of charge to callers requesting them. Further information: Nikki Hill Carers National Association, 20-25 Glasshouse Yard, London EC1A 4JS. CarersLine: 01345573 369.

\section{New publications}

Staying Sane. How to make your mind work for you by Raj Persaud is now available from Metro Publishing for $\$ 17.99$ (hb). Further information: 19 Gerrard Street, London WIV 7LA (Telephone: 0171734 6766/Fax: 6866).

Domestic Violence-Making a Difference, produced by $\mathrm{NCH}$ Action for Children follows Hidden Victims, their earlier publication on the same theme. Both publications are avallable from Information, 85 Highbury Park, London N5 IUD (Telephone: 01717047121 ).

Depression: A guide to its recognition and management in General Practice is a guide for effective recognition, diagnosis and management of depression produced by a working Party from Neurolink. Copies are avallable through the Neurolink Hotline on 0345023070. 